\title{
Implementation of a standardized surgical technique and peri-operative care pathway in robot- assisted restorative rectal cancer resection. A single center cohort study
}

Jacob Damgaard Eriksen ( $\sim$ jacoerik@rm.dk)

Aarhus University Hospital: Aarhus Universitetshospital https://orcid.org/0000-0002-2781-582X

Henriette Vind Thaysen

Aarhus University Hospital: Aarhus Universitetshospital

Katrine Jøssing Emmertsen

Randers Regional Hospital: Regionshospitalet Randers

Anders Husted Madsen

Regional Hospital West Jutland

Anders Tøttrup

Aarhus University Hospital: Aarhus Universitetshospital

Charlotte Buchard Nørager

Aarhus University Hospital: Aarhus Universitetshospital

Ken Ljungmann

Aarhus University Hospital: Aarhus Universitetshospital

Niels Thomassen

Aarhus University Hospital: Aarhus Universitetshospital

Conor P. Delaney

Cleveland Clinic Florida

Lene Hjerrild Iversen

Aarhus University Hospital: Aarhus Universitetshospital

\section{Research Article}

Keywords: Rectal cancer, Surgery, Robot, Standardization, Implementation, Anastomotic leakage

Posted Date: March 2nd, 2022

DOI: https://doi.org/10.21203/rs.3.rs-1039136/v1

License: (9) This work is licensed under a Creative Commons Attribution 4.0 International License.

Read Full License 
Page $2 / 21$ 


\section{Abstract}

\section{Background}

Despite increasing focus on the technical performance of total mesorectal excision over recent decades, anastomotic leakage (AL) continues to be a frequent and serious complication for many patients, even in the hands of experienced surgical teams. This study describes implementation of standardized technical surgical and combined peri-operative care protocols in an effort to reduce variability, decrease the risk of anastomotic leakage, and improve associated short-term outcomes for rectal cancer patients undergoing robot-assisted restorative rectal resection (RRR).

Methods

We evaluated all rectal cancer patients undergoing robot-assisted RRR at Aarhus University Hospital between 2017 and 2020. Six standardized surgical steps directed to improve anastomotic healing were mandatory for all RRR. Additional changes were made during the period with prohibition of systemic dexamethasone and limiting the use of endoscopic stapling devices.

Results

The use of the full standardization, including all six surgical steps, increased from $40.3 \%(95 \% \mathrm{Cl}, 0.28$ 0.54) to $86.2 \%(95 \% \mathrm{Cl}, 0.68-0.95)$. The risk of $\mathrm{AL}$ decreased from $21.0 \%(95 \% \mathrm{Cl}, 0.12-0.33)$ to $6.9 \%$ (95\% $\mathrm{Cl}, 0.01-0.23$ ). Length of hospital stay (LOS) decreased from 6 days (range 2-50) to 5 days (range 2-26). The rate of patients readmitted within 90 days decreased from $21.0 \%(95 \% \mathrm{Cl}, 0.12-0.33)$, to $6.9 \%(95 \% \mathrm{Cl}$, $0.01-0.23)$.

Conclusion

The full standardization was effectively implemented for rectal cancer patients undergoing robot-assisted RRR. The risk of AL, LOS and readmission decreased during the study period. A team focus on highreliability and peri-operative complications can improve patient outcomes.

\section{Background}

Colorectal cancer is the third most common cancer worldwide, and rectal cancer accounts for approximately one third of the total colorectal cancer incidence(1). In 1982, RJ Heald introduced the concept of total mesorectal excision (TME)(2). TME is fundamental in modern sphincter-preserving rectal resection with an anastomosis i.e. restorative rectal resection (RRR). RRR was originally performed by an open approach, but with the introduction of laparoscopic surgery and later robot-assisted surgery, many rectal cancer centers perform RRR with robot-assisted approach. Minimally invasive surgery has proven to be oncologically comparable to open approach(3)(4)(5)(6)(7). Furthermore, it has been demonstrated that patients undergoing minimally invasive RRR have an improved postoperative recovery compared to patients undergoing surgery with open approach(7)(8). 
Despite improvements in surgical treatment, one major issue continues to challenge colorectal surgeons worldwide - the risk of anastomotic leakage (AL). AL is negatively associated with overall survival $(9,10)$, increased risk of recurrence(11), and is negatively associated with long-term functional outcome(12). Studies have reported the risk of $A L$ to vary from 0 to $>20 \%$, although various definitions of $A L$ challenge comparison between the studies $(9,13-17)$. Standardization of surgery has been suggested to improve short-term outcome for patients as well as oncological and functional outcome(18)(19)(20)(21)(22). However, standardization has not been implemented in many rectal centers including our department. In recognition of a persistently high risk of AL following robot-assisted RRR(23), our department decided to implement a standardized surgical approach with the aim of decreasing the risk of AL. Such standardization of the surgical technique in RRR, with one or more specific surgical steps, has been reported using laparoscopic approach $(18-21,24)$, but not with robot-assisted approach. Furthermore, the studies have not described whether it was possible to implement the full standardization or whether various surgeons with different levels of experience, surgical unpredictability and heterogeneity of patients hindered implementation of the full standardization.

Our department decided to implement a specific standardized technique for RRR which has previously been applied at Cleveland Clinic, Ohio(18) and has resulted in low AL rates. The standardized technique was introduced by Professor Dr. Conor P. Delaney (CPD) and consists of a number of specific surgical steps.

The primary aim of this study was to evaluate the process of implementing a standardized technique, for all rectal cancer patients undergoing robot-assisted RRR to reduce variability in outcomes. Specifically, besides evaluating the implementation process, we aimed to evaluate the risk of anastomotic leakage during and after the implementation as well as length of hospital stay and the readmission rate within 90 days.

\section{Methods}

\section{Design and settings}

This single centre cohort study was conducted on all rectal cancer patients undergoing intended minimally invasive RRR at Aarhus University Hospital (AUH) between the 16th of October 2017 and the 14th of October 2020. AUH is one of two primary referral centres managing all rectal cancer surgery in Central Denmark Region, with a population of approximately 1.3 mill inhabitants. The annual volume of RRR is in the range of 60-75 at $\mathrm{AUH}(25)$. Peri-operatively, all patients underwent a multimodal fast-track regimen(26). The study was approved by The Danish Data Protection Agency (j.nr. 1-16-02-11-18), Danish Patient Safety Authority (case number 3-3013-3006/1), and Central Denmark Region (case number 1-4570-47-20)

\section{Cohort}


All patients with rectal cancer located within $15 \mathrm{~cm}$ from the anal verge undergoing intended minimally invasive RRR were included. Patients who underwent primary open approach were excluded.

\section{Surgical setting}

All resections were elective. The surgical strategy for each patient was decided at a multi-disciplinary team meeting including specialists in colorectal cancer surgery, radiology, oncology, and pathology. The surgical approach was robot-assisted laparoscopy as first choice. In case of lack of capacity for robotassisted surgery, laparoscopic surgery was performed. Depending on tumour location measured as distance from the anal verge (tumour height), PME or TME was planned (27). As routine, a defunctioning loop-ileostomy was created only when TME was performed.

All surgeons were proficient in both robot-assisted and laparoscopic surgery. At least one certified colorectal consultant surgeon participated in each operation. When a training fellow performed the operation, a certified colorectal surgeon supervised the operation.

\section{The intervention:}

The standardization of surgical steps for robot-assisted RRR at AUH was implemented from the 16th of October 2017 and included the following steps:

1. Central ligation of the inferior mesenteric artery (IMA) proximally to the left colic artery

2. Central ligation of inferior mesenteric vein (IMV) just below the pancreas

3. Mobilization of the splenic flexure

4. Transection of the anococcygeal raphe (only for TME)

5. Perpendicular transection of rectum

6. Confirmation of arterial bleeding from an arcade artery of the distal colon before performing the anastomosis

7. Perforation of the spike from the circular stapler straight through the stapler line or just in front of the stapler line (optional)

\section{The process of implementing the standardization}

In the Spring of 2017, Professor Dr. CPD from Cleveland Clinic, Ohio, USA, visited AUH. In a one-hour morning session, colorectal surgeons from AUH were taught and instructed in the standardization by CPD. The same day, CPD participated in two RRRs to evaluate a few of the surgeons. Four colorectal surgeons were supervised by CPD. CPD constructed a detailed description (supplementary material 1) on how to perform a standardized RRR with anastomosis. The consultant surgeons at AUH discussed the description and agreed on the final standardization as described above. However, the surgeons realized that it could be difficult to determine if step 7 was performed. Therefore, step 7 was made optional.

The standardization was mandatory for all intended minimally invasive RRR for rectal cancer patients. However, surgeons were allowed to deviate from it. Immediately after surgery, the surgeon registered on a 
written form if steps 1-6 were performed (supplementary material 2). In case of deviation from the standardization, the surgeon had to list the reason for the deviation on the written form. All anastomoses were circular double stapled.

In a two-week period in January 2018, two AUH surgeons were on on-site visit at Cleveland Clinic to observe the performance of the standardized RRR.

Throughout the study period, the surgeons at AUH evaluated the standardization and the risk of AL at two meetings in August 2018 and February 2020, respectively. Based on persistently high AL rate, the meetings led to the following changes:

1. From September 2018: Preoperative systemic dexamethasone administration was prohibited. Transection of the rectum with an endoscopic stapler was prohibited in males having TME, and transection should be performed through a Pfannenstiel incision and using a Contour or TA stapler.

2. From March 2020: Transection of the rectum with an endoscopic stapler was allowed in PME only, and if the surgeon anticipated using only one or two firings/magazines. Otherwise, transection was performed through a Pfannenstiel incision and a Contour or TA stapler.

Based on the two meetings, the study was divided into three periods: Period 1 (October 2017 - August 2018), period 2 (September 2018 - February 2020), and period 3 (March 2020 - October 2020).

\section{Data sources}

The written form (supplementary material 2), which was filled in by the surgeons immediately postsurgery, included the following data: Name of the surgeons, times of start and end of surgery, intraoperative bleeding, patient weight and height, use of Indocyanine green (ICG), type of stapler used for transection of the rectum, number of firings (if the stapler was endoscopic), name of circular stapler, type of anastomosis (i.e. side-to-end, end-to-end, other), besides information on whether steps 1-6 of the standardization were performed (yes/no), and if not, the reasons for the deviation. In patients with no registered form or missing data, the steps in the standardization were retrieved from medical records by JDE (who did not participate in or performed any of the RRRs). JDE entered the form data in the Redcap database(28). Data on ASA, smoking, alcohol intake, neoadjuvant therapy, tumour height, preoperative systemic dexamethasone administration, defunctioning stoma, length of hospital stay (LOS), AL within 30 days, readmission within 90 days, and death within 90 days were retrieved from medical records (reviewed by JDE).

\section{Outcome}

The evaluation of implementation was based on the complete usage of the standardization. If all of steps 1-6 were followed (step 4 for TME only), implementation of the standardization was defined as 'yes'. If deviation from at least one of the six steps occurred, implementation of the standardization was defined as 'no'. 
AL was defined as a defect of the intestine in relation to the anastomosis leading to communication between the intra and extra luminal compartments (29). A pelvic abscess without a proven defect in the stapler line was included as an AL. Severity of AL was graded according to the definition from The International Study Group of Rectal Cancer (29). Only symptomatic AL was included; hence, grade A AL was not included. Patients were diagnosed with AL by computed tomography with rectal contrast, endoscopy, or reoperation because of clinical symptoms and/or biochemical analyses, suggestive of AL according to clinical practice. Patients were registered as readmitted, if they were readmitted one or more times within 90 days following discharge after surgery. The total number of days readmitted was defined as all days registered as an in-hospital patient within 90 days following discharge after surgery.

\section{Statistics}

Statistical analysis was performed in Stata/SE 15.1 (StataCorp LLC, College Station, Texas, USA). Continuous data were transformed into categorical variables and presented as numbers and percentages. Usage of the standardization was defined as the proportion of RRR procedures in which a full standardization was used, i.e., steps 1-6, among the entire number of minimally invasive RRR procedures. A sub-analysis was performed calculating the proportion of RRR procedures in which a full standardization was used among patients with a registered form. The absolute risk of AL was calculated as proportion of patients undergoing RRR who developed AL within 30 days. The rate of patients readmitted was calculated as proportion of patients readmitted within 90 days. To compare the usage of the surgical standardization, the risk of AL, the LOS, and the rate of patients readmitted between the tree periods, Kruskal-Wallis test was used. $P$-value $<0.05$ was considered statistically significant.

\section{Results}

A total of 165 patients with rectal cancer underwent minimal invasive RRR at AUH between the 16th of October 2017 and the 14th of October 2020. Ten different surgeons performed the operations as the primary surgeon. The surgeons were all either certified colorectal surgeons or training fellows in colorectal surgery. Patient characteristics are presented in Table 1. A timeline illustrating the interventions throughout the study period with implementation of the standardization, and the additional changes with prohibition of systemic dexamethasone and limited use of the endoscopic stapler is presented in Figure 1. 
Table 1

Characteristics of patients with rectal cancer undergoing robot-assisted restorative rectal resection at Aarhus University Hospital, 2017-2020. Number (percentages), unless indicated otherwise

\begin{tabular}{|c|c|c|c|}
\hline & $\begin{array}{l}\text { Period 1: } \\
\text { October } 2017 \text { - } \\
\text { August } 2018\end{array}$ & $\begin{array}{l}\text { Period 2: } \\
\text { September } 2018 \text { - } \\
\text { February } 2020\end{array}$ & $\begin{array}{l}\text { Period 3: } \\
\text { March } 2020- \\
\text { October } 2020\end{array}$ \\
\hline N patients & 62 & 74 & 29 \\
\hline \multicolumn{4}{|l|}{ Sex } \\
\hline Males & $47(75.8)$ & $43(58.1)$ & $22(75.9)$ \\
\hline Females & $15(24.2)$ & $31(41.9)$ & $7(24.1)$ \\
\hline Median, age, years (range) & $66(43-84)$ & $67(39-91)$ & $61(45-80)$ \\
\hline Median BMI, kg/m² (range) & $26(19-42)$ & $26(16-43)$ & $26(20-35)$ \\
\hline \multicolumn{4}{|c|}{$\begin{array}{l}\text { American Society of Anesthesiology } \\
\text { score (ASA) }\end{array}$} \\
\hline 1 & $14(22.6)$ & $22(29.7)$ & $11(37.9)$ \\
\hline 2 & $39(62.9)$ & $45(60.8)$ & $16(55.2)$ \\
\hline 3 & $9(14.5)$ & $7(9.5)$ & $1(3.4)$ \\
\hline Missing & 0 & 0 & $1(3.4)$ \\
\hline \multicolumn{4}{|l|}{ Smoking } \\
\hline Never & $23(37.1)$ & $41(55.4)$ & $13(44.8)$ \\
\hline Previous ( $\geq 8$ weeks) & $25(40.3)$ & $17(23.0)$ & $10(34.5)$ \\
\hline Current & $14(22.6)$ & $16(21.6)$ & $6(20.7)$ \\
\hline \multicolumn{4}{|l|}{ Alcohol intake/week (units) } \\
\hline 0 & $1(1.6)$ & $6(8.1)$ & $6(20.7)$ \\
\hline $1-14$ & $56(90.3)$ & $65(87.8)$ & $21(72.4)$ \\
\hline $15-20$ & $3(4.8)$ & $2(2.7)$ & $1(3.4)$ \\
\hline$\geq 21$ & $2(3.2)$ & $1(1.4)$ & $1(3.4)$ \\
\hline \multicolumn{4}{|c|}{ Neoadjuvant (chemo)radio-therapy } \\
\hline No & $55(88.7)$ & $60(81.1)$ & $23(79.3)$ \\
\hline Yes & $7(11.3)$ & $14(18.9)$ & $6(20.7)$ \\
\hline
\end{tabular}




\begin{tabular}{|c|c|c|c|}
\hline & $\begin{array}{l}\text { Period 1: } \\
\text { October } 2017 \text { - } \\
\text { August } 2018\end{array}$ & $\begin{array}{l}\text { Period 2: } \\
\text { September } 2018 \text { - } \\
\text { February } 2020\end{array}$ & $\begin{array}{l}\text { Period 3: } \\
\text { March } 2020- \\
\text { October } 2020\end{array}$ \\
\hline \multicolumn{4}{|c|}{ Tumor height (cm from anal verge) } \\
\hline $11-15 \mathrm{~cm}$ & $34(54.8)$ & $41(55.4)$ & $13(44.8)$ \\
\hline $6-10 \mathrm{~cm}$ & $25(40.3)$ & $26(35.1)$ & $15(51.7)$ \\
\hline$\leq 5 \mathrm{~cm}$ from anal verge & $3(4.8)$ & 0 & 0 \\
\hline Missing & 0 & $7(9.5)$ & $1(3.4)$ \\
\hline \multicolumn{4}{|c|}{$\begin{array}{l}\text { Surgery by certified colorectal } \\
\text { surgeon }\end{array}$} \\
\hline No & $6(9.7)$ & $3(4.1)$ & $1(3.4)$ \\
\hline Yes & $56(90.3)$ & 71 (95.9) & $28(96.6)$ \\
\hline \multicolumn{4}{|l|}{ Dexamethasone } \\
\hline No & $14(22.6)$ & $70(94.6)$ & $28(96.6)$ \\
\hline Yes & $48(77.4)$ & $4(5.4)$ & $1(3.4)$ \\
\hline \multicolumn{4}{|l|}{ Surgical Approach } \\
\hline Robotic & $59(95.2)$ & $71(95.9)$ & $29(100)$ \\
\hline Laparoscopic & $3(4.8)$ & $3(4.1)$ & 0 \\
\hline \multicolumn{4}{|c|}{ Converted from minimally invasive } \\
\hline No & $60(96.8)$ & $73(98.6)$ & $28(96.6)$ \\
\hline Yes & $2(3.2)$ & $1(1.4)$ & $1(3.4)$ \\
\hline \multicolumn{4}{|l|}{ Resection type } \\
\hline TME & $42(67.7)$ & $48(64.9)$ & $16(55.2)$ \\
\hline PME & $20(32.3)$ & $26(35.1)$ & $13(44.8)$ \\
\hline \multicolumn{4}{|l|}{ Missing } \\
\hline \multicolumn{4}{|c|}{$\begin{array}{l}\text { Stapler (type) used for transection of } \\
\text { distal rectum }\end{array}$} \\
\hline Robot & $52(83.9)$ & $36(48.6)$ & 3 (10.3) \\
\hline EndoGIA & $4(6.5)$ & $3(4.1)$ & 0 \\
\hline
\end{tabular}

$\mathrm{BMI}$, body mass index; TME, total mesorectal excision; PME, partial mesorectal excision, TA, thoracoabdominal 


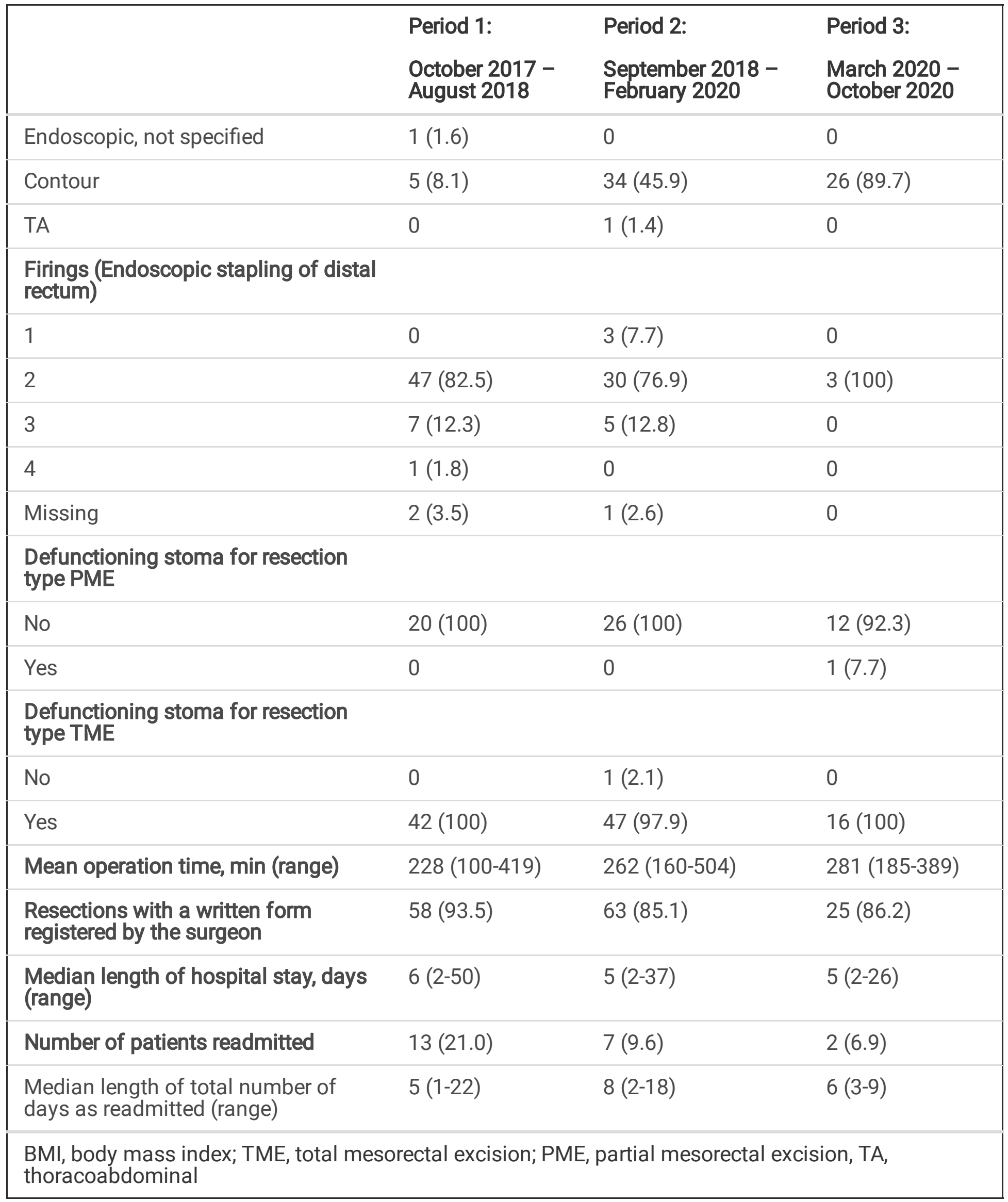

A total of $88.5 \%$ of the patients had a written form registered by the surgeon immediately after the operation. Table 2 demonstrates the fulfilment of the specific steps in the standardization based on the 
form registration or medical records. From period 1 to period 3 usage of the standardization increased from $40.3 \%(95 \% \mathrm{Cl}, 0.28-0.54)$, over $66.2 \%(0.54-0.77)$ in period 2 to $86.2 \%(95 \% \mathrm{Cl}, 0.68-0.95)(p<0.001)$ (Figure 2). A sub-analysis was performed excluding patients with no registered form, and in this sub analysis usage of the standardization increased throughout the periods from $43.1 \%(95 \% \mathrm{Cl}, 0.30-0.57)$ to $96.0 \%(95 \% \mathrm{Cl}, 0.80-1.00)$. 
Table 2

Patients with rectal cancer undergoing robot-assisted restorative rectal resection with at Aarhus University Hospital, 2017-2020 and the specific steps in the standardization based on the written form registered by the surgeon immediately after the operation or review of medical records. Number (percentages)

\begin{tabular}{|c|c|c|c|}
\hline & $\begin{array}{l}\text { Period 1: } \\
\text { October } 2017 \text { - } \\
\text { August } 2018\end{array}$ & $\begin{array}{l}\text { Period 2: } \\
\text { September } 2018 \text { - } \\
\text { February } 2020\end{array}$ & $\begin{array}{l}\text { Period 3: } \\
\text { March } 2020- \\
\text { October } 2020\end{array}$ \\
\hline \multicolumn{4}{|c|}{$\begin{array}{l}\text { Central transection of IMA (high } \\
\text { ligation) }\end{array}$} \\
\hline No & $23(37.1)$ & $10(13.5)$ & $1(3.4)$ \\
\hline Yes & $34(54.8)$ & $55(74.3)$ & $25(86.2)$ \\
\hline Missing & $5(8.1)$ & $9(12.2)$ & $3(10.3)$ \\
\hline \multicolumn{4}{|c|}{ Central transection of IMV } \\
\hline No & $23(37.1)$ & $4(5.4)$ & 0 \\
\hline Yes & $35(56.5)$ & $66(89.2)$ & $28(96.6)$ \\
\hline Missing & $4(6.5)$ & $4(5.4)$ & $1(3.4)$ \\
\hline \multicolumn{4}{|c|}{ Mobilization of splenic flexure } \\
\hline No & $20(32.3)$ & $5(6.8)$ & 0 \\
\hline Yes & $41(66.1)$ & $69(93.2)$ & $29(100)$ \\
\hline Missing & $1(1.6)$ & 0 & 0 \\
\hline \multicolumn{4}{|c|}{$\begin{array}{l}\text { Transection of the } \\
\text { anococcygale ligament (TME) }\end{array}$} \\
\hline No & 0 & 0 & 0 \\
\hline Yes & $40(95.2)$ & $41(85.4)$ & $15(93.8)$ \\
\hline Missing & $2(4.8)$ & $7(14.6)$ & $1(6.3)$ \\
\hline \multicolumn{4}{|c|}{$\begin{array}{l}\text { Perpendicular transection of } \\
\text { rectum }\end{array}$} \\
\hline No & 0 & 0 & 0 \\
\hline Yes & $56(90.3)$ & $61(82.4)$ & $26(89.7)$ \\
\hline Missing & $6(9.7)$ & $13(17.6)$ & $3(10.3)$ \\
\hline
\end{tabular}

IMA, inferior mesenteric artery; IMV, inferior mesenteric vein; TME, total mesorectal excision 


\begin{tabular}{|llll|}
\hline & $\begin{array}{l}\text { Period 1: } \\
\text { October 2017 - } \\
\text { August 2018 }\end{array}$ & $\begin{array}{l}\text { Period 2: } \\
\text { September 2018 - }\end{array}$ & $\begin{array}{l}\text { Period 3: } \\
\text { Farch 2020 - } \\
\text { October 2020 }\end{array}$ \\
\hline No & $2(3.2)$ & 0 & 0 \\
\hline Yes & $59(95.2)$ & $72(97.3)$ & $28(96.6)$ \\
\hline Missing & $1(1.6)$ & $2(2.7)$ & $1(3.4)$ \\
\hline IMA, inferior mesenteric artery; IMV, inferior mesenteric vein; TME, total mesorectal excision
\end{tabular}

AL occurred in 24 patients (14.5\%) (Table 3 ). AL was verified with computed tomography with rectal contrast extravasation and/or endoscopy with a defect in 22 patients. Two patients with AL had a pelvic abscess without a proven defect in the stapler line. From period 1 to period 3 the risk of AL decreased from $21.0 \%(95 \% \mathrm{Cl}, 0.12-0.33)$, over $12.2 \%(95 \% \mathrm{Cl}, 0.06-0.22)$ in period 2 to $6.9 \%(95 \% \mathrm{Cl}, 0.01-0.23)$, respectively $(p=0.15)$. LOS decreased from 6 days (range 2-50) over 5 days (range $2-37)(p=0.55)$, to 5 days (range 2-26) ( $p=0.55)$. The rate of patients readmitted within 90 days decreased from $21.0 \%(95 \% \mathrm{Cl}$, $0.12-0.33)$, over $9.6 \%(95 \% \mathrm{Cl}, 0.39-0.19)$, to $6.9 \%(95 \% \mathrm{Cl}, 0.01-0.23)(p=0.08)$.

Table 3

The proportion of anastomotic leakage with rectal cancer patients undergoing robot-assisted restorative rectal resection at Aarhus University Hospital, 2017-2020. Number/total and proportion (95\% Cl), unless indicated otherwise.

\begin{tabular}{|llll|}
\hline & $\begin{array}{l}\text { Period 1: } \\
\text { October 2017 - August } \\
\mathbf{2 0 1 8}\end{array}$ & $\begin{array}{l}\text { Period 2: } \\
\text { September 2018 - February } \\
\mathbf{2 0 2 0}\end{array}$ & $\begin{array}{l}\text { Period 3: } \\
\text { March 2020 - October }\end{array}$ \\
\hline $\begin{array}{l}\text { Anastomotic } \\
\text { leak }\end{array}$ & $13 / 6221.0 \%(0.12-0.33)$ & $9 / 7412.2 \%(0.06-0.22)$ & $2 / 296.9 \%(0.01-0.23)$ \\
\hline Type B (n) & 11 & 8 & 2 \\
\hline Type C (n) & 2 & 1 & 0 \\
\hline
\end{tabular}

\section{Discussion}

In this prospective cohort study of patients undergoing robot-assisted RRR, we evaluated the process of implementing a standardization of surgical steps aiming to reduce the risk of AL. We found that the usage of the standardization increased statistically significant throughout the study period. Additional changes were made with prohibition of systemic dexamethasone administration and limited use of endoscopic stapler to transect the rectum. The changes were launched immediately after each decision, and they were followed almost completely. During the study period, the risk of AL, LOS and the rate of patients readmitted decreased, however not significantly. 
This study clearly indicates that it is feasible to implement a standardization of a surgical procedure at a department employing several surgeons. There is no clear evidence of the effect of the individual steps in the standardization and the additional changes on the risk of AL. However, there is evidence that the risk of $A L$ is multifactorial $(30,31)$. Therefore, it seems important to standardize treatment as much as possible. This will potentially decrease the risk of confounding in future studies investigating the risk of $A L$ after RRR. If various centers agree on the same standardized treatment, this could also decrease the heterogeneity when performing multicenter studies. The current study is the first of its kind to describe an implementation of technical aspects of robot-assisted RRR, and whether it was feasible in every operation and with several surgeons. However, implementation of other regimens has been published. Conn et al described important factors for successful implementation of Enhanced Recovery After Surgery (ERAS)-program in colorectal surgery(32). They experienced that belief in the importance of the program, and making the program highly visible were key elements for a successful implementation. We experienced similar important factors for the implementation of the standardization. In particular, three factors were found to be important; 1: Our department had experienced a period of time with a high occurrence of AL which made the surgeons highly motivated for adjustments that could potentially lower the risk of AL. 2: All surgeons at the department participated in the planning of the standardization, and eventually agreed upon the standardization. 3: Data regarding usage of the standardization and the risk of AL were presented at the two evaluation meetings which made it visible, whether the standardization was followed or not. Other approaches could have potentially accelerated the implementation with closer evaluation of each individual surgeon's usage of the standardization. However, we wanted to create a realistic clinical setting, which could be transferred to other colorectal centers.

We implemented the standardization to lower the risk of $\mathrm{AL}$, and supplemented with additional changes (prohibition of systemic dexamethasone administration, limiting the use of endoscopic stapler devices), and the subsequent decline in the risk of $A L$ was successful. However, the study is underpowered to perform multivariate analysis or to draw any valid conclusions on those topics. LOS and the rate of readmitted patients decreased as the risk of $A L$ decreased. The criteria for discharging patients remained unchanged in the study period. A decrease in LOS and the rate of readmitted patient will benefit the patients, and furthermore, it will have a positive impact on health economics.

\section{The elements in the standardized approach and the association with $\mathrm{AL}$}

The different steps in the standardized approach described in this study and their association with AL have been subjects to debate since the procedure was first described.

The level of ligation of IMA (high tie versus low tie) and the association with AL have been described in randomized controlled trials, meta-analysis and population-based cohort studies, and there is no consensus whether high tie or low tie should be preferred to decrease the risk of $\mathrm{AL}(33-35)$. Regarding splenic flexure mobilization (SFM) it is debated whether to perform routine SFM or selective SFM when tension on the anastomosis occurs. Advocates for routine SFM argue that it is not possible to assess the 
tension on the anastomosis because no formal measurement of anastomotic tension exist(36). Furthermore, they argue that it is preferable to perform a standardized procedure, and it is most optimal to perform SFM before doing the pelvic operation(36). Advocates for selective SFM argue that SFM increases operation time, and increases the risk of iatrogenic damage to the spleen(37), and there is no need to undertake an additional surgical step, if the anastomosis can be safely constructed without undue tension(38). Transection of the anococcygeal raphe (only for TME), perpendicular transection of rectum, and confirmation of arterial bleeding from an arcade artery of the distal colon before performing the anastomosis were all steps included in our standardization based on a general consideration on how to perform a safe anastomosis.

It has been well documented that glucocorticoid (GC) including dexamethasone reduces the magnitude of the postoperative stress response(39), and enhances patients' postoperative recovery with decreased risk of vomiting and nausea $(40,41)$. However, GCs' effect on the risk of AL has been a subject for debate. In the randomized controlled DREAMS Trial(40), 1350 patients were allocated to standard induction of anesthesia with or without $8 \mathrm{mg}$ intravenous dexamethasone to reduce postoperative vomiting. No differences were found in surgical adverse effects, and the risk ratio of AL within 30 days with patients receiving dexamethasone versus standard induction of anesthesia was $0.53(0.26-1.08)$. Thus, the study concluded that dexamethasone did not increase the risk of AL. However, only $42.4 \%$ of the patients underwent rectal resection and the rest of the surgeries were performed on colon and the small bowel. Potential predictors of AL like neoadjuvant treatment and BMI were not reported. Few patients $(2.4 \%)$ had $A L$, and there were no details on after which type of resections AL occurred. A cohort study with 4172 patients with Crohn's disease undergoing anastomosis plus ileostomy demonstrated steroid use as an independent risk factor for AL (Odds Ratio: 1.4, 95\% Cl 1.03 - 2.0)(42). However, they assessed steroid use for chronic conditions and the result is not transferable to cancer patients receiving a single dose of steroid perioperative. Our center decided to omit dexamethasone in recognition of a persistently high AL rate of up to $16 \%$ following introduction of dexamethasone for all RRR (23).

Along with implementation of minimally invasive approach, it has become possible to transect the distal rectum with an endoscopic stapler, which is an alternative stapler type to the ones used during the classical open approach. Due to stapling in the deep narrow pelvis and a suboptimal cutting angle, the need for multiple magazines/firings often occurs. Several studies have demonstrated that the risk of AL increases with use of the endoscopic stapler and the number of magazines/firings. In particular, when the number of magazines/firings exceeds $2(17,31,43,44)$. This study clearly demonstrated that it was feasible for the surgeons to follow the instructions to perform stapling of the distal rectum with an endoscopic stapling technique with maximum two magazines/firings or otherwise to choose an open stapling technique.

There were a few study limitations. The study cohort was small; the surgeons could have been prone to the Hawthorne effect(45), which could have made the surgeons perform surgery with other routines than those planned. However, this study aimed to evaluate the implementation of the standardization, hence the Hawthorne effect would not influence the results. Furthermore, the Hawthorne effect and attention to 
detail could possible improve the team focus and patient outcomes. Finally, there was no control with the written form filled out by the surgeon, and incorrect registration could have occurred - intentionally or unintentionally. Incorrect registration of the written form would not have influenced the risk of AL.

\section{Conclusion}

In conclusion, this study describes the evaluation of implementing the standardization for all rectal cancer patients undergoing robot-assisted RRR at AUH. Additional changes to the perioperative protocol were made and effected immediately, and the risk of AL decreased during the study period. We recommend testing the standardization in a larger setting. A team focus on high-reliability and perioperative complications can improve patient outcomes.

\section{Declarations}

Ethics approval and consent to participate. The study was approved by The Danish Data Protection Agency (j.nr. 1-16-02-11-18), Danish Patient Safety Authority (case number 3-3013-3006/1), and Central Denmark Region (case number 1-45-70-47-20).

Consent for publication. Not applicable.

Availability of data and materials. The data that support the findings of this study are available from Central Denmark Region but restrictions apply to the availability of these data, which were used under license for the current study, and so are not publicly available. Data are however available from the authors upon reasonable request and with permission of The Danish Data Protection Agency, Danish Patient Safety Authority, and Central Denmark Region.

Competing interests. The authors declare that they have no competing interests.

Funding. Danish Cancer Society. Grant number R204-A12668. The funders had no impact in study design, data collection and analysis, decision to publish, or preparation of the manuscript.

Authors' contributions. All authors contributed to the design of the study. JDE, LHI, HVT, AT, CBN, KL, NT and CPD were major contributor in implementing the surgical standardization. JDE and LHI analyzed the results. JDE, HVT, KJE, AHM, AT, CBN, KL, NT, CPD and LHI and interpreted the results. JDE drafted the work, which $\mathrm{LI}, \mathrm{AHM}, \mathrm{KE}, \mathrm{CPD}$ and $\mathrm{AT}$ each contributed with revisions. All authors read and approved the final manuscript.

Acknowledgments. Danish Cancer Society is acknowledged for funding this study.

\section{References}

1. Cancer Today [Internet]. Available from: https://gco.iarc.fr/today/home (Accessed: 19 October 2021) 
2. Heald RJ, Husband EM, Ryall RDH. The mesorectum in rectal cancer surgery-the clue to pelvic recurrence? Br J Surg. 1982;69(10):613-6.

3. Schnitzbauer V, Gerken M, Benz S, Völkel V, Draeger T, Fürst A, et al. Laparoscopic and open surgery in rectal cancer patients in Germany: short and long-term results of a large 10-year population-based cohort. Surg Endosc [Internet]. 2020;34(3):1132-41. Available from: https://doi.org/10.1007/s00464019-06861-4

4. Fleshman J, Branda ME, Sargent DJ, Boller AM, George V V., Abbas MA, et al. Disease-free Survival and Local Recurrence for Laparoscopic Resection Compared With Open Resection of Stage II to III Rectal Cancer: Follow-up Results of the ACOSOG Z6051 Randomized Controlled Trial. Ann Surg. 2019;269(4):589-95.

5. Bonjer HJ, Deijen CL, Abis GA, Cuesta MA, van der Pas MHGM, de Lange-de Klerk ESM, et al. A Randomized Trial of Laparoscopic versus Open Surgery for Rectal Cancer. N Engl J Med. 2015;372(14):1324-32.

6. Jeong SY, Park JW, Nam BH, Kim S, Kang SB, Lim SB, et al. Open versus laparoscopic surgery for mid-rectal or low-rectal cancer after neoadjuvant chemoradiotherapy (COREAN trial): Survival outcomes of an open-label, non-inferiority, randomised controlled trial. Lancet Oncol [Internet]. 2014;15(7):767-74. Available from: http://dx.doi.org/10.1016/S1470-2045(14)70205-0

7. Vennix S, Pelzers L, Bouvy N, Beets G I., Pierie J-P, Wiggers T, et al. Laparoscopic versus open Total Mesorectal Excision for rectal cancer (Review). Cochrane Database Syst Rev. 2014;(4).

8. van der Pas MHGM, Haglind E, Cuesta MA, Fürst A, Lacy AM, Hop WCJ, et al. Laparoscopic versus open surgery for rectal cancer (COLOR II): Short-term outcomes of a randomised, phase 3 trial. Lancet Oncol. 2013;14(3):210-8.

9. Den Dulk M, Marijnen CAM, Collette L, Putter H, Påahlman L, Folkesson J, et al. Multicentre analysis of oncological and survival outcomes following anastomotic leakage after rectal cancer surgery. $\mathrm{Br} J$ Surg. 2009;96(9):1066-75.

10. Boström P, Haapamäki MM, Rutegård J, Matthiessen P, Rutegård M. Population-based cohort study of the impact on postoperative mortality of anastomotic leakage after anterior resection for rectal cancer. BJS open. 2019;3(1):106-11.

11. Hain E, Maggiori L, Manceau G, Mongin C, Prost à la Denise J, Panis Y. Oncological impact of anastomotic leakage after laparoscopic mesorectal excision. Br J Surg. 2017;104(3):288-95.

12. Kverneng Hultberg D, Svensson J, Jutesten $H$, Rutegård J, Matthiessen P, Lydrup $M-L$, et al. The impact of anastomotic leakage on long-term function after anterior resection for rectal cancer. Dis Colon Rectum. 2020;63(5):619-28.

13. Arezzo A, Migliore M, Chiaro P, Arolfo S, Filippini C, Di Cuonzo D, et al. The REAL (REctal Anastomotic Leak) score for prediction of anastomotic leak after rectal cancer surgery. Tech Coloproctol. 2019;23(7):649-63.

14. Matthiessen $P$, Hallböök $O$, Rutegård J, Simert G, Sjödahl R. Defunctioning stoma reduces symptomatic anastomotic leakage after low anterior resection of the rectum for cancer: A 
randomized multicenter trial. Ann Surg. 2007;246(2):207-14.

15. Ellebæk MB, Rahr HB, Boye S, Fristrup C, Qvist N. Detection of early anastomotic leakage by intraperitoneal microdialysis after low anterior resection for rectal cancer: a prospective cohort study. Color Dis. 2019;21(12):1387-96.

16. Bertelsen CA, Andreasen AH, Jørgensen $\mathrm{T}$, Harling $\mathrm{H}$. Anastomotic leakage after anterior resection for rectal cancer: Risk factors. Color Dis. 2010;12(1):37-43.

17. Sciuto A, Merola G, De Palma GD, Sodo M, Pirozzi F, Bracale UM, et al. Predictive factors for anastomotic leakage after laparoscopic colorectal surgery. World J Gastroenterol. 2018;24(21):2247-60.

18. Lindsetmo RO, Delaney CP. A standardized technique for laparoscopic rectal resection. J Gastrointest Surg. 2009;13(11):2059-63.

19. Lindsetmo RO, Champagne B, Delaney CP. Laparoscopic rectal resections and fast-track surgery: what can be expected? Am J Surg [Internet]. 2009;197(3):408-12. Available from: http://dx.doi.org/10.1016/j.amjsurg.2008.11.009

20. Aslak KK, Bulut O. The implementation of a standardized approach to laparoscopic rectal surgery. $J$ Soc Laparoendosc Surg. 2012;16(2):264-70.

21. Miskovic D, Foster J, Agha A, Delaney CP, Francis N, Hasegawa H, et al. Standardization of laparoscopic total mesorectal excision for rectal cancer: A structured international expert consensus. Ann Surg. 2015;261(4):716-22.

22. Lange MM, Martz JE, Ramdeen B, Brooks V, Boachie-Adjei K, Van De Velde CJH, et al. Long-term results of rectal cancer surgery with a systematical operative approach. Ann Surg Oncol. 2013;20(6):1806-15.

23. Danish Colorectal Cancer Group. Annual reports [Internet]. Available from: https://dccg.dk/aarsrapporter-2/\#1507126473001-9d745f05-b165 (Accessed: 19 October 2021)

24. Bullock M, Nasir IUI, Hemandas A, Qureshi T, Figueiredo N, Heald R, et al. Standardised approach to laparoscopic total mesorectal excision for rectal cancer: a prospective multi-centre analysis. Langenbeck's Arch Surg. 2019;404(5):547-55.

25. Danish Colorectal Cancer Group. Annual report 2018 [Internet]. [cited 2021 Mar 23]. Available from: https://dccg.dk/wp-content/uploads/2019/11/DCCG-Klinisk-basisrapport-2018.pdf

26. Christensen HK, Thaysen H V., Rodt SÅ, Carlsson P, Laurberg S. Short hospital stay and low complication rate are possible with a fully implemented fast-track model after elective colonic surgery. Eur Surg Res. 2011;46(3):156-61.

27. Danish Colorectal Cancer Group. National guideline for mesorectal excision [Internet]. Available from: https://dccg.dk/wp-content/uploads/2017/08/2014_rectumanatomi.pdf (Accessed: 15 March 2020)

28. REDCap [Internet]. [cited 2021 Mar 4]. Available from: https://redcap.au.dk/index.php? action=myprojects 
29. Rahbari NN, Weitz J, Hohenberger W, Heald RJ, Moran B, Ulrich A, et al. Definition and grading of anastomotic leakage following anterior resection of the rectum: A proposal by the International Study Group of Rectal Cancer. Surgery. 2010;147(3):339-51.

30. McDermott FD, Heeney A, Kelly ME, Steele RJ, Carlson GL, Winter DC. Systematic review of preoperative, intraoperative and postoperative risk factors for colorectal anastomotic leaks. $\mathrm{Br} \mathrm{J}$ Surg. 2015;102(5):462-79.

31. Park JS, Choi GS, Kim SH, Kim HR, Kim NK, Lee KY, et al. Multicenter analysis of risk factors for anastomotic leakage after laparoscopic rectal cancer excision: The Korean laparoscopic colorectal surgery study group. Ann Surg. 2013;257(4):665-71.

32. Gotlib Conn L, McKenzie M, Pearsall EA, McLeod RS. Successful implementation of an enhanced recovery after surgery programme for elective colorectal surgery: A process evaluation of champions' experiences. Implement Sci [Internet]. 2015;10(1):1-11. Available from: http://dx.doi.org/10.1186/s13012-015-0289-y

33. Hajibandeh S, Hajibandeh S, Maw A. Meta-analysis and trial sequential analysis of randomized controlled trials comparing high and low ligation of the inferior mesenteric artery in rectal cancer surgery. Dis Colon Rectum. 2020;63(7):988-99.

34. Zeng J, Su G. High ligation of the inferior mesenteric artery during sigmoid colon and rectal cancer surgery increases the risk of anastomotic leakage: A meta-analysis. World J Surg Oncol. 2018;16(1):1-11.

35. Rutegård $\mathrm{M}$, Hemmingsson $\mathrm{O}$, Matthiessen $\mathrm{P}$, Rutegård J. High tie in anterior resection for rectal cancer confers no increased risk of anastomotic leakage. Br J Surg. 2012;99(1):127-32.

36. Ludwig KA, Kosinski L. Is splenic flexure mobilization necessary in laparoscopic anterior resection another view. Dis Colon Rectum. 2012;55(11):1198-200.

37. Masoomi H, Carmichael JC, Mills S, Ketana N, Dolich MO, Stamos MJ. Predictive factors of splenic injury in colorectal surgery: Data from the nationwide inpatient sample, 2006-2008. Arch Surg. 2012;147(4):324-9.

38. Chand M, Miskovic D, Parvaiz AC. Is splenic flexure mobilization necessary in laparoscopic anterior resection. Dis Colon Rectum. 2012;55(11):1195-7.

39. McSorley ST, Horgan PG, McMillan DC. The impact of preoperative corticosteroids on the systemic inflammatory response and postoperative complications following surgery for gastrointestinal cancer: A systematic review and meta-analysis. Crit Rev Oncol Hematol [Internet]. 2016;101(2016):139-50. Available from: http://dx.doi.org/10.1016/j.critrevonc.2016.03.011

40. Collaborators DT, Midlands W. Dexamethasone versus standard treatment for postoperative nausea and vomiting in gastrointestinal surgery: randomised controlled trial (DREAMS Trial). BMJ. 2017;357:j1455.

41. Srinivasa S, Kahokehr AA, Yu TC, Hill AG. Preoperative glucocorticoid use in major abdominal surgery: Systematic review and meta-analysis of randomized trials. Ann Surg. 2011;254(2):183-91. 
42. Neary PM, Aiello AC, Stocchi L, Shawki S, Hull T, Steele SR, et al. High-Risk lleocolic Anastomoses for Crohn's Disease: When Is Diversion Indicated? J Crohn's Colitis. 2019;13(7):856-63.

43. Balciscueta Z, Uribe N, Caubet L, López M, Torrijo I, Tabet J, et al. Impact of the number of stapler firings on anastomotic leakage in laparoscopic rectal surgery: a systematic review and metaanalysis. Tech Coloproctol. 2020;24(9):919-25.

44. Qu H, Liu Y, Bi D song. Clinical risk factors for anastomotic leakage after laparoscopic anterior resection for rectal cancer: a systematic review and meta-analysis. Surg Endosc. 2015;29(12):360817.

45. Dowling WF. Hawthorne Revisited: The Legend and the Legacy. Organ Dyn. 1975;3(3):66-80.

\section{Figures}

Dexamethasone was prohibited

Transection of rectum with an endoscopic stapler was prohibited with males undergoing

TME

Transection of rectum with an endoscopic stapler was allowed in PME only and with $\leq 2$ firings/mazine

TME, total mesorectal excision; PME, partial mesorectal excision

\section{Figure 1}

Timeline of the study period, October $16^{\text {th }} 2017$ - October $14^{\text {th }} 2020$ with the standardized changes throughout the period with rectal cancer patients undergoing intended robot-assisted restorative rectal resection at Aarhus University Hospital. 


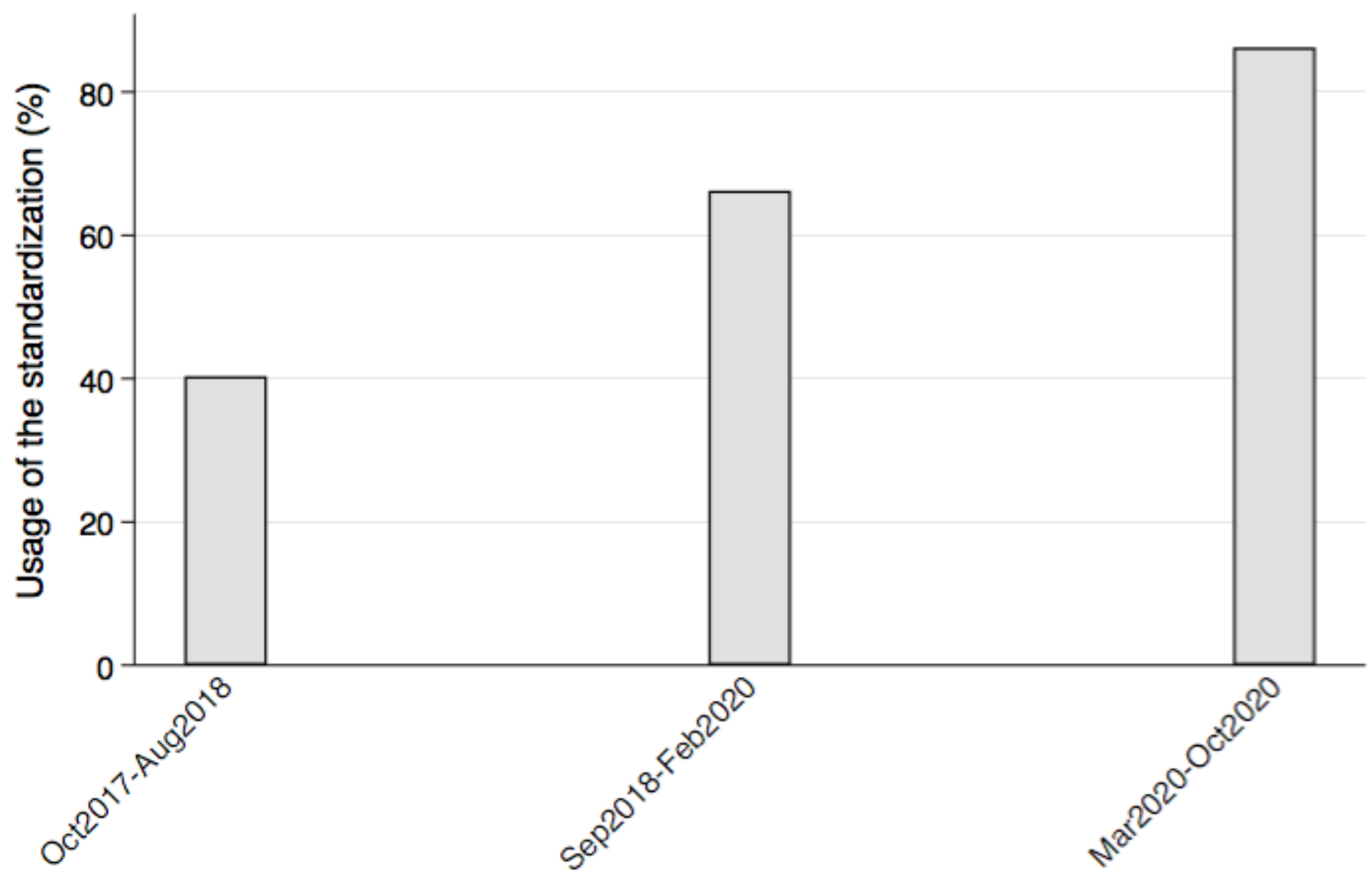

Figure 2

Rectal cancer patients undergoing restorative rectal resection (RRR) with an intended robot-assisted approach at Aarhus University Hospital (AUH), 2017-2020 and with usage of the standardization.

\section{Supplementary Files}

This is a list of supplementary files associated with this preprint. Click to download.

- Supplementarymaterial1.docx

- Supplementarymaterial2.docx 